\title{
Alquife, un castillo con vocación minera en el Zenete (Granada)
}

\author{
José Ma Martín Civantos *
}

\begin{abstract}
RESUMEN
El castillo de Alquife es uno de los más importantes del Zenete, una zona de intenso poblamiento en época medieval, caracterizado por las grandes vegas de agricultura intensiva de regadío y por la explotación minera. Alquife es, en este sentido, el máximo exponente en la extracción de mineral de hierro a partir del s. XI tras un proceso concentración de la producción. Tras la conquista castellana, la implantación del señorío introducirá cambios radicales.
\end{abstract}

PALABRAS CLAVE: Arqueología medieval, poblamiento rural, castillo, minería y metalúrgia.

\section{INTRODUCCIÓN}

El municipio de Alquife es uno de los ocho que componen el Marquesado del Zenete. Esta comarca se sitúa en la cara Norte de Sierra Nevada y se extiende desde sus cumbres, al Sur, hasta las de la Sierra de Baza, al Norte, atravesando el valle del Zalabí. Sus límites Este y Oeste vienen marcados por la provincia de Almería y la Hoya de Guadix.

La primera característica que sorprende en su paisaje es la brusquedad del contacto entre las vertientes montañosas de Sierra Nevada y la llanura ligeramente inclinada que se extiende hacia el Norte. Pero más allá de esa pri-

\begin{abstract}
The Alquife castle is one of the most importants in the Zenete (Granada), in an area of intense settlement during the medieval period caracterized by the intensive irrigated agriculture and the mining explotation. Alquife is, in this sense, the principal producer of iron since the Xlth century after a process of production concentration. After the castilian conquest, the creation of a manor will introduce radical changes.
\end{abstract}

KEY WORDS: Medieval Archaeology, rural settlement, castle, mining and metalurgy.

mera impresión, creada por los contrastes de volúmenes, se percibe rápidamente la existencia, a lo largo de la linea que separa los dos dominios topográficos, de una banda estrecha y sensiblemente irregular en su trazado, sobre la que se concentran los paisajes más humanizados. Esta franja, de un kilómetro de ancho tal vez, se dilata, a intervalos, para penetrar en la montaña en busca de los fondos de valle. Hacia el Norte, la transición con el altiplano, a unos 1000-1200 m de altitud, es menos brusca por el dominio del cultivo que se prolonga sin solución de continuidad. No obstante, este límite septentrional está jalonado por una serie de cerros desprendidos de la masa principal de la sierra. En efecto, las características del par-

* Universidad de Granada. 
celario se modifican y constatamos que la localización de los últimos pueblos, hacia el Norte, está estrechamente ligada a esa alineación de relieves aislados (HUMBERT, 1988: p. 12).

Así pues, podemos apreciar tres dominios yuxtapuestos de Sur a Norte: la sierra, el altiplano $y$, en medio, una estrecha franja de transición, donde se localizan los ocho pueblos que conforman el Zenete y sus respectivas vegas.

Los términos municipales se organizan perpendicularmente a esta orientación, en estrechas franjas que se extienden de Norte a Sur ocupando prácticamente toda la longitud posible entre la cumbre de Sierra Nevada y la Sierra de Baza. Las únicas excepciones son las de Alquife y La Calahorra, que no poseen más que un poco de montaña al Sur y cubren esencialmente una fracción del altiplano incluyendo alguno de los cerros aislados que preceden a la sierra. A esto debemos añadir la reciente creación del municipio de Charches, en la falda de la Sierra de Baza, antigua aldea de La Calahorra que rompe parte de este esquema pero del que no nos ocuparemos en esta ocasión. Esta estructura municipal, incluyendo la antigua adscripción de Charches, será fundamental para comprender la formación del territorio y su desarrollo.

Dos son los elementos antrópicos que más destacan del paisaje: las extensas vegas que llevan los regadíos desde los fondos de valle hasta bien entrado el altiplano y la minería, especialmente sobresaliente en el caso de Alquife. La extensión del regadío es posible, no sólo por la existencia de unos recursos hídricos abundantes procedentes de las nieves de Sierra Nevada, que cumple una función de "pantano natural", sino también gracias al control y organización de esos recursos en una extensa red de infraestructuras hidráulicas compuesta por numerosas acequias, balsas y aljibes (MARTIN CIVANTOS, en prensa).

La importancia de la minería en todo el Zenete radica en las características de la estructura geológica de la región. Se encuentra esta enclavada en el denominado complejo Nevado-Filábride, cuya secuencia litoestratigráfica, de abajo a arriba, esta formada por una serie metapelítica paleozóica -más antigua-, compuesta por micasquistos grafitosos y cuarcitas; una serie permotriásica constituida por micasquistos plateados, cuarcitas, gneises y anfibolitas $-y$ episodios de serpentinas como el del Barranco de S. Juan y Cerro del Almirez-; por último, la cobertera triásica está compuesta por rocas carbonatadas, fundamentalmente mármoles (RUIZ MONTES, 1991: p. 187).

Los procesos metalogénicos dan lugar a dos tipos de mineralizaciones diferentes:

- De una parte, en la serie paleozóica abundan sobre todo las filonianas, que se han interpretado como resultado del relleno de fracturas por soluciones mineralizadoras que removilizaron elementos dispersos en las rocas $y$, eventualmente, mineralizaciones estratoligadas preexistentes. Básicamente son del mismo tipo que las existentes desde Sierra Nevada hasta Sierra Almagrera: el relleno fundamental es de siderita acompañada de un cortejo de sulfuros y sulfosales con hierro, cobre, plomo, antimonio, plata, bismuto y mercurio -también algo de oro y barita-; ha sido la proporción de unas u otras especies minerales, y de sus productos de alteración, lo que condicionó, en su día, el laboreo prioritario como minas de hierro, cobre, plata... No obstante, su estructura las hace hoy carecer de todo interés económico.

- Sin embargo, los más importantes yacimientos de hierro de las Béticas son mineralizaciones estratoligadas en los mármoles permotriásicos o triásicos. Son concordantes y se encuentran en relación espacial y/o genética con los estratos de la roca que las aloja, bien sea porque la mineralización fue coetánea de la sedimentación -mineralizaciones sinsedimentarias-; porque se concentró durante la diagénesis del sedimento -mineralizacinoes sindiagenéticas-, o bien porque soluciones mineralizadoras encontraron determinados horizontes particularmente reactivos -mineralizaciones de sustitución metasomática. Bien entendido que a estos procesos sucedieron otros -meta- 
morfismo, hidrotermalismo, alteración meteórica- que produjeron rellenos de fracturas y cavidades y alteraciones que son las responsables de la conformación última de las mineralizaciones. A ellas corresponden formaciones del tipo hematites y goethitas -óxidos e hidróxidos de hierro- (RUIZ MONTES, 1991: p. 188. Fig. I).

A este último tipo pertenecen las mineralizaciones de las imponentes Minas del Marquesado, comenzadas a explotar a final del siglo XIX (COHEN, 1987) entre los pueblos de Alquife y La Calahorra, de las que se extrae hierro junto a mármoles nevado-filábrides. Dentro de este conjunto encontramos el cerro del castillo de Alquife, sobre el actual pueblo y al Norte de este, dominando al mismo tiempo las minas practicadas en el cerro y la amplia y fertil vega que se extiende desde el pie de monte hacia el valle. Hoy definitivamente clausuradas, el cierre de las minas supone para la comarca el fin de una larga historia de actividad no sólo extractiva, sino también metalúrgica, dedicada fundamentalmente al hierro, pero también al cobre y a la plata.

\section{EL POBLAMIENTO}

No es este el lugar para analizar en detalle el poblamiento y su relación con la actividad minera del Zenete aunque son escasísimos los trabajos realizados en la zona hasta el presente. Es muy poco lo que sabemos sobre época prehistórica, aunque sin duda la presencia humana debió de ser significativa y unida a la existencia de mineral. Así parece ser también en el periodo ibérico del que se conoce algo más (GONZÁLEZ ROMÁN et alii, 1997). Según M. BERTRAND et alii (1996: pp. 182- I83), se intensificó la explotación mediante la instalación de grandes centros fortificados como Cerro Zorrero, Cardal, el de las minas de Lanteira o el Peñón de Arruta. Estos mismos autores dan como seguro un descenso de la actividad bajo el dominio romano aunque, dado el actual nivel de conocimientos, tal vez debería matizarse esta afirmación. Así se desprende también de la toponimia, ya que Ferreira y Lanteira son dos denominaciones de origen latino con una clara alusión a la actividad minera del hierro y la plata. Durante la Antigüedad tardía y la Alta Edad Media se produciría una reactivación de la minería con el surgimiento en los ss. V-VI de nuevos talleres de tamaño relativamente grande junto a las zonas de explotación pero siempre concentrados sobre las cimas de altas colinas.

La conquista árabo-beréber marcaría un punto de inflexión en la evolución y organización de la producción con la proliferación de pequeños centros, dando lugar a una atomización de las labores de extracción y transformación del mineral de hierro. Así ocurre también en otras zonas de Europa durante la Alta Edad Media como la Toscana (FRANCOVICH, 1991). Muchos de estos centros serán posteriormente abandonados con el final de periodo emiral, aunque algunos mantienen su actividad hasta el siglo XI y principios del XII (BERTRAND et alii, 1996: pp. I84-185 y MARTíN CIVANTOS, inédito). Efectivamente, esta nueva reorganización del espacio y del poblamiento debe coincidir con el establecimiento de una red de alquerías a lo largo del s. $X$ y Xl y una nueva orientación del sistema productivo con la extensión de la agricultura de regadío que supondrá una amplia transformación del territorio. Es posible que en época zirí existiera ya una red castral más o menos configurada puesto que fue lugar de fricción entre la taifa almeriense y la granadina (LÉVI PROVENiAL y GARCÍA GÓMEZ, 1980: p. 131). La campaña de Alfonso I de Aragón en I I25-I I 26 pone igualmente de manifiesto la consolidada existencia de núcleos rurales. Idrīīi en el siglo XII menciona Ferreira y Dólar con sus respectivas vegas en la ruta de Almería a Granada por Fiñana (IDRĪIT̄, 1989: p. 90). Sin embargo, el argumento más significativo lo encontramos en los documentos árabes publicados por González Palencia (GONZÁLEZ PALENCIA, 1940 y 1941). El más antiguo de ellos, copia del año 1286 del original de I | 87, es un pleito entre las alquerías de Lubros y Bartiliana (seguramente las actuales Lugros y Purullena), por las aguas para el riego. En él se mencionan algunas estructuras hidráulicas $y$, sobre todo, se hace uso de la alusión a derechos adquiridos antiguamente y a una organización de usos y riegos consolidada. Igualmente ocurre con el repartimiento del cercano río Alhama de Gua- 
dix del año II 39 (MOLINA LÓPEZ, 1991 y ESPINAR MORENO, 1987).

La reorganización del poblamiento y del territorio $y$, sobre todo, la nueva orientación de las estrategias productivas de la zona no significan, necesariamente, un descenso de la producción minera, sino probablemente eso mismo: una nueva forma de organización de la actividad extractiva y metalúrgica. Seguramente el abandono de asentamientos conllevará una concentración de la producción que se realizará no sólo en Alquife, sino también en algunos otros lugares como Lanteira, para la extracción de plata, en el que se han encontrado restos cerámicos (MALPICA CUELLO, 1996: p. 267) o en Jeres, donde se sigue explotando el cobre en 1330 (GONZÁLEZ PALENCIA, 1940: p. 331). Ahora bien, a partir de este momento, la siderurgia tendrá un papel definido, importante, pero no hegemónico. Otra cuestión sería intentar determinar el papel que desempeñó en este proceso cada uno de los agentes: estado, comunidades campesinas, clases urbanas...Por ahora, sin embargo, no podemos más que enunciar muchos de estos interrogantes e hipótesis a la espera de reunir más datos.

Lo que si parece más seguro es que Alquife se configura desde ese momento, y sobre todo en época nazarí, en el principal centro productor de hierro del Zenete. Las huellas de la actividad extractiva son evidentes a pesar de las modificaciones y derrumbes posteriores. No ocurre lo mismo con las de la transformación del mineral si bien es posible encontrar algunas escorias en el cerro, sobre todo embutidas en la obra del castillo, como parte del mortero o incluso decorando el rejuntado de los mampuestos. El hecho de que no se encuentren apenas escorias en relación al volumen extractivo puede deberse a dos razones: por un lado al posible traslado de parte del mineral a la vecina ciudad de Guadix, de la que Ibn al-Jațib dice que "posee minas de hierro" y que sus principales industrias "son las del hierro y la de la seda" (IBN AL-JAṬīB, 1997: pp I30-131). Además, entre |494-| 497 en un documento conservado en el Archivo Histórico Municipal de Guadix "dize la çibdad, que le haga merçed que los vezinos desta çibdad puedan traer de la tierra del hierro del minar del çenete syn pagar derechos ningunos nin otra cosa, pues que antiguamente lo solían traer" ' . Por otro lado, es bastante probable la explotación de escombreras y escoriales por parte de la compañía de minas concesionaria en época contemporánea. En cualquier caso hoy no nos es posible calibrar la capacidad de transformación del mineral hasta que no se realice una excavación y un análisis mucho más detallado.

Sea como fuere, no existe ninguna mención escrita en las fuentes medievales a la actividad minera de Alquife, tal vez porque, aunque importante, ocupaba un lugar secundario respecto a la orientación agrícola de la alquería. Se realiza así una opción por una estrategia de desarrollo en un sentido muy concreto: una región montañosa y con grandes recursos minerales opta por la agricultura intensiva de regadío, desarrollando amplias vegas en las que tendrán un papel fundamental los cultivos dedicados a la exportación: la seda y los frutos secos. Esto no quiere decir ni mucho menos, que las otras actividades, la minería y la ganadería, no se encuentren presentes y no gocen de importancia. De hecho, es normal que la producción de las comunidades andalusíes no esté dirigida a la explotación de un único recurso ${ }^{2}$.

Tras la conquista cristiana en 1489, Guadix sigue siendo un importante centro siderúrgico gracias, en buena medida, al mineral llegado de

\footnotetext{
I Memorial de la ciudad de Guadix. Archivo Histórico Municipal de Guadix. Pieza 5/2I. |494-|497. Ed. por ESPINAR MORENO, M., ÁlVAREZ DEL CASTILLO, M. A. y GUERRERO LAFUENTE, M.D.: La ciudad de Guadix en los siglos XV y XVI (I 490-15 I5), p. 74.

2 Un claro ejemplo lo encontramos en la alquería de La Malahá, a escasos kilómetros de Granada, que compatibiliza la actividad agrícola con las salinas existentes en la localidad. Ver TRILLO SAN JOSÉ, C.: "Los diferentes aprovechamientos del agua en una alquería del Reino de Granada: La Malahá, del distrito del Quempe", en Agricultura y Regadío en al-Andalus. II Coloquio de Historia y Medio Físico. Granada, 1996, pp. 215-228.
} 
Alquife. Sin embargo, como veremos más adelante, van a aparecer dos centros más en sendos pueblos cercanos: uno en Jéres y otro en Lugros, provistos de fuelles y martillos hidráulicos. Esto habría supuesto según M. Bertrand una intensificación de la explotación y una transformación del territorio por la cantidad de madera requerida en los trabajos de fundición (BERTRAND et alii, 1996: p. 189).

\section{EL CASTILLO}

Casi nada nos puede aportar la toponimia. C. Asenjo Sedano afirma que Alquife proviene del latín ciphus, que significa cerro (ASENJO SEDANO, 1992: p. 54), sin embargo, no hemos podido encontrar este vocablo en ningún diccionario latino, ni hay indicios de un asentamiento o explotación romana en la colina. Si hemos encontrado algún resto de cerámica ibérica que podría significar una explotación temporal o aislada, pero que no es suficiente como para ubicar en él un poblamiento estable. Más probable en cambio podría ser su origen árabe al-kahf, que significa cueva. En el Empadronamiento que realiza el marqués en I 550 aparece con el nombre de al-kihf, como resultado de la 'imãla típica del dialectal andalusí ${ }^{3}$. El nombre, a la vista del cerro y de las minas, parece apropiado, pero puede tener una doble lectura: si el topónimo se hubiera fijado en el momento de constitución del castillo y la alquería, querría decir que las cuevas, esto es, las minas, son anteriores, si no es así, quiere decir que lo habría hecho con posterioridad, cuando estas cuevas comenzaran a aparecer como fruto de la explotación minera.

Los restos del castillo se encuentran, como ya hemos dicho, sobre el cerro situado al Norte del actual pueblo propiedad de la Compañía Andaluza de Minas, a 1252 m sobre el nivel del mar. Aunque ya ha sido descrito de forma somera (MALPICA CUELLO, 1996: pp. 124-125 y MARTÍN GARCÍA et alii, 1999: pp. 93-94), merece la pena que hagamos un repaso para seguidamente entrar en más detalles (Figs. 2 y 3). El estado de conservación es, en general, malo. No obstante pueden observarse buena parte de sus estructuras. La fortaleza parece tener una forma pentagonal alargada en dirección Este-Oeste. Actualmente se puede seguir buena parte de su perímetro, del que se conservan restos claros de seis torres. No se aprecian restos de la entra$\mathrm{da}$, que posiblemente se encontrara en el lado Sur, el más destruido y en el que, como veremos, se encontraba la alquería.

Dentro del recinto encontramos, en la zona $\mathrm{NO}$, un aljibe de pequeñas dimensiones y con una sola nave que no conserva la bóveda. Sus medidas son de $5,85 \mathrm{~m}$ por 3,20, con una profundidad máxima hasta el comienzo del relleno de 2,50 m. En el centro, en la parte más elevada del recinto, hay restos de muros de mampostería enrasados con el terreno y líneas de rotura que conforman varios espacios de habitación de difícil interpretación. Bien podría tratarse de la distribución interna de la fortaleza $o$ incluso de una torre a modo de homenaje o algún aljibe más completamente enterrado.

En la ladera Sur, como ya hemos dicho, se ubica la antigua alquería andalusí. Aquí hemos encontrado abundante cerámica y material de construcción. Entre este algunas tejas, no demasiadas, aunque no debe extrañarnos si pensamos que los tejados debieran ser planos, esto es, terrazas de cañizo, esquistos y launa como en la parte antigua del actual pueblo y como el resto de la arquitectura tradicional de Sierra Nevada. Pero sin duda, el hecho más significativo es la existencia, en los perfiles dejados por las minas a cielo abierto y sus derrumbes, de muros de mampostería y de un relleno que en algunos puntos llega a ser considerable. Sin embargo, no nos es posible establecer si este poblamiento se encuentra dentro o fuera de las murallas. La dirección de la torre más oriental del recinto parece indicar que 3 Archivo Histórico Nacional. Sección Osuna. Leg. 1870-2, estudiado en el caso de La Calahorra por ESPINAR MORENO et alii,
1986. 
sí debía abarcarlo, pero la gran acumulación de piedras a media ladera -probablemente una torre- y la cercanía de las minas lleva a pensar que está extramuros. Tampoco podemos saber nada sobre el entramado urbano o su extensión. Si es posible que llegara hasta el llano donde hoy se localiza el pueblo es difícil de precisar. Aunque la iglesia fue edificada originalmente sobre el solar de la antigua mezquita, Asenjo Sedano afirma que es posible que se reconstruyera en un lugar distinto a juzgar por el mal estado de conservación que presentaba esta en el siglo XVII (ASENJO SEDANO, 1992: pp. 54-56). El templo se encuentra junto a la calle Acequia. Esta canalización marcaría la línea de rigidez del área de regadío y, si es que no cambió de sitio, al igual que ocurre en la vecina Alpujarra, el contacto entre la vega y la alquería a través de la mezquita y su fuente.

En el castillo pueden distinguirse cuatro técnicas constructivas y una variante con carácter decorativo. La primera es un tapial hormigonado que encontramos, como es habitual, en el aljibe. La segunda es un tapial de cal y cantos en el que están construidas las dos torres orientales (Fig. 5) y los paños de muralla que las unen entre sí y con la siguiente torre al NO, justo al Norte del punto geodésico. Igualmente son de cal y canto el lienzo entre esta última torre y la siguiente hacia el $\bigcirc$ de mamposteria y, al $\mathrm{S}$, el que hay al $\mathrm{E}$ de la torre del ángulo SO. Por último también encontramos, como continuación más oriental del anterior, un pequeño trozo bajo el resto de una torre de tapial calicastrado practicamente destruida por los derrumbes de una de las explotaciones mineras.

De tapial calicastrado es, además del fragmento al que nos acabamos de referir, la torre $\mathrm{SO}$ (Fig. 8) y la de la esquina NO, la muralla que las une y la que une la última con la torre de mampostería más al E, así como el resto de muralla que parece hacer un quiebro al $S$ del punto geodésico. El tapial se apoya, como es normal, sobre una base de mampostería que nivela el terreno para comenzar a encofrar y aisla de la humedad. En el lado $O$ aún son visibles algunos palos de mechinales y tablillas, cuerdas y huellas de las agujas en el encofra- do. Dos aspectos llaman la atención sobre las estructuras construidas con esta técnica: una en la muralla $\bigcirc$, de la que se conserva un resto de altura considerable entre las dos torres de las esquinas. Aquí se conserva la cara del tapial en el interior pero no en el exterior excepto en el primer cajón de abajo. Sin embargo algunos mampuestos de los cajones superiores sobresalen de la línea de fachada, lo que pudiera indicar que podría haber existido en algún momento una torre intermedia. Este hecho podría venir reforzado por la presencia, en ese cajón inferior, de la huella de una aguja vertical semicircular, de gran grosor, en el interior el encofrado. Hasta ahora desconocemos su función, pero se trata indudablemente de un elemento para dar mayor rigidez y resistencia a las tablas y está relacionado con el encofrado de grandes masas de mortero, es decir, torres. Así encontramos por ejemplo otras tres marcas en otras tres torres del mismo castillo. El segundo aspecto que llama la atención es que la torre NO (Fig. 6) ha sido claramente reparada mediante un forro de mampostería que cubre el relleno del tapial sólo en el lado $O$. No debe tratarse de una reforma intencionada ya que sólo afecta a uno de sus cuatro lados y no es un simple forro sobre la cara del tapial igual que ocurre en otros castillos del Reino Nazarí de Granada, sino que la torre ha sido cortada irregularmente y sobre ella se adosa un nuevo mortero más claro, más rico y resistente que el relleno del calicastrado y de mampuestos más grandes. Sobre este está el muro de mampostería, más alto que la base del mismo material para el tapial. La obra presenta, además, una curiosa decoración en el rejuntado de las piedras con incisiones verticales y paralelas en el mortero y fragmentos de mineral y escoria embutidos. Esta forma decorativa distingue además esta obra de la base de mampostería del tapial perfectamente conservada en la torre SO por ejemplo.

Por último encontramos, como ya hemos dicho, algunas partes construidas en mampostería (Figs. 6 y 7), como la reforma de la torre $\mathrm{NO}$ a la que nos acabamos de referir. La siguiente torre hacia el E (TNI) es obra de mampostería en su totalidad. Conserva casi completas las fachadas $\mathrm{O}$ y $\mathrm{N}$ y una conside- 
rable altura. Está macizada por un relleno relativamente pobre en cal. En su cara S, la que da al interior del recinto, es posible apreciar la unión con la muralla que, recordemos, hacia el $O$ es de tapial calicastrado y hacia el E de cal y canto. Aunque difícilmente, se observa una esquina de un cajón del tapial calicastrado a ras del suelo sobre el que se apoya el relleno de la torre que es, por lo tanto, claramente posterior. A este relleno se le apoya, a su vez, un muro de 0,5 $\mathrm{m}$ de ancho por 2 $\mathrm{m}$ de largo que sale de la misma cara $\mathrm{S}$ en dirección S-SE, hacia el punto geodésico. Es también de mampostería sin yagueado y con el mismo relleno. Cabe no obstante señalar un aspecto aún más interesante de esta torre: también presenta la decoración con mineral de hierro y escorias anteriormente descrita, pero sólo en la zona inferior izquierda de la fachada $\mathrm{N}$ y no en el resto a pesar de conservarse buena parte del rejuntado de los mampuestos (Fig. 7). Pudiera tratarse pues, de una nueva reparación aunque no sabemos si anterior o posterior. En esta misma zona, algo más abajo, se puede apreciar claramente la esquina de la fachada rehundida y rejuntada. No parece que pueda ser fruto de un error constructivo, ni de un deslizamiento del terreno, sino más bien de una nueva reparación. A nuestro juicio, podría ser un resto de la base de mampostería de una torre anterior de tapial, igual a la del $\mathrm{NO}$, que, tras ser totalmente destruida fue rehecha en mampostería. Por último, aún más hacia el E encontramos otra torre. Son sólo algunos mampuestos en línea y parte de un relleno de mortero que no nos permiten decir si estamos ante otra torre de mampostería o la base del mismo material de una de tapial.

Con este primer análisis y los restos de cerámica hallados es posible establecer algunas cronologías relativas y absolutas y algunas hipótesis para una posterior comprobación. Parece obvio que la última fase del castillo, la más importante quizás, es la nazarí. Estratigráficame, parece también claro que la últmia fase constructiva es la de mampostería, con una subfase tal vez, la de la decoración, de la que no nos sería posible decir cual es anterior. Tampoco hay muchas dudas de que las obras rea- lizadas en tapial calicastrado son igualmente nazaríes o tal vez almohades por la cerámica incrustada en el mortero. Son, sin embargo, como hemos dicho, anteriores a la mampostería, tal y como ha quedado demostrado estratigráficamente. El cal y canto no contiene cerámica ni tampoco mineral ni escoria. Debe ser, según queda reflejado también en el análisis estratigráfico, la construcción más antigua, tal vez de la época fundacional del castillo. Pero, ¿cual sería esta? Hemos encontrado algunos fragmentos cerámicos ibéricos que, por su volumen, no parecen indicar una ocupación continua del cerro. Tampoco sería este el caso en época altomedieval, aunque si hay algo más de cerámica adscribible al siglo $X$. Los vestigios más antiguos y lo suficientemente abundantes podemos datarlos en el siglo $\mathrm{Xl}$, fecha que coincide con la época de formación de las vegas y la red de alquerías iniciada, tal vez, durante el califato. Por otra parte, no debemos olvidar que esta es una zona de fricción con el reino taifa de Almería que llegó a controlar todo este sector, ni los inicios de la agresión feudal del $\mathrm{N}$ con Alfonso VI de Castilla y, a comienzos del siglo XII, con Alfonso el Batallador. Es posible que el siglo Xl fuera el inicio de una explotación sistemática del hierro, aunque hubiera habido episodios más o menos aislados en la Antigüedad y la alta Edad Media. La técnica del cal y canto no era tampoco desconocida en la época. Así, la propia alcazaba de Granada construida por los ziríes está hecha con este material y esta técnica. ¿Podría entonces responder a un programa estatal de construcción que pudiera incluir la creación de importantes fortalezas y/o villas fortificadas como la de Illora también en Granada? ¿Quiere decir esto que existió un primer recinto de cal y canto más grande? ¿Por qué se extiende tanto hacia el Este? ¿Porque engloba parte del poblamiento tal vez? ¿Para controlar la actividad minera del cerro? ¿Porque dentro se realiza parte del proceso de transformación del mineral? ¿O se trata simplemente de un refugio? No parece que tenga mucho sentido construir un albacar junto a la población sin englobarla y sin que el castillo esté en relación con una red de alquerías más amplia, al menos hasta donde sabemos. Debería estar por tanto en función de la actividad productiva del hierro o tal vez pudiera 
tratarse de una villa. iTendría entonces una alcazaba en la parte más alta, la occidental, donde se adivinan los restos de la división interna y se encuentra el aljibe? ¿Sería entonces esa posible alcazaba la restaurada en época nazar? ¿Supondría esto una reducción del espacio defensivo? Son muchas las incógnitas que quedarán sin respuesta al menos hasta que se realice una excavación arqueológica del yacimiento. Algunos indicios parecen sin embargo apuntar en el sentido de los interrogantes: el deterioro del castillo es mucho más visible en la parte oriental, la de cal y canto, que en la occidental y son, además, destrozos claramente intencionados tal y como se ve en la disposición vertical de algunos fragmentos de muralla y el socavamiento de la base de mampostería de las dos torres más orientales.

Lo que está claro es que tras la capitulación de 1489 ante los castellanos y la concesión del Zenete como señorío al Cardenal Mendoza, la fortaleza debió ser abandonada y seguramente desmochada en este momento o tras la rebelión de los mudéjares diez años después. Tal vez sea a este momento al que correspondan los desmantelamientos a los que acabamos de hacer mención, aunque resulta significativo que sólo se encuentren en la zona oriental del castillo, en las estructuras de cal y canto, y no en la occidental.

\section{LA MINERÍA}

Es ahora, con la conquista castellana, cuando debió de comenzar el proceso de transformación del cerro hasta llegar al paisaje que podemos contemplar hoy. En torno a las ruinas del castillo que coronan la elevación de mármoles y mineral de hierro, encontramos numerosas cavidades y cortes en la roca, algunos de un tamaño verdaderamente considerable, otros son simples bocas de galerías y pozos. El largo período de explotación -como mínimo desde el siglo XI hasta mediados del XXy las transformaciones causadas por los derrumbes de galeríasy paredes de cavas hacen muy difícil una interpretación. No obstante, tras un primer análisis se distinguen con claridad cuatro tipos de explotación: a) Un arranque o arañado superficial del mineral que aflora y que ni siquiera llega a ser una trinchera muchas veces.

b) Otras veces si llega a hacerse trinchera que puede convertirse en un pozo más o menos vertical pero, en cualquier caso, se sigue siempre la veta de mineral y es, por tanto, irregular. No parece tener una gran extensión en nigún caso y no alcanza una gran profundidad (Fig. 10).

c) La tercera la constituye un sistema de pozos verticales y galerías transversales que no siguen el filón. Es una explotación regular, a veces solo con un carácter de prospección, realizada desde finales del siglo XIX y a lo largo del XX (Fig. 9).

d) La última son las cavas o rozas a cielo abierto tan visibles a lo largo de todo el perímetro del cerro y hoy parcialmente arruinadas por los desprendimientos de cornisas y paredes. Pueden seguir una masa de mineral o no, lo que determina que su forma sea lenticular o pueda llegar a asemejarse a la de una gran trinchera (Figs. 8-10). El ejemplo más destacado y, sin duda excepcional, es la gran cava comenzada a abrir en el llano en 1931 cuyas escombreras son visibles desde todo el Zenete.

No hay restos de escombreras excepto las ya señaladas y las de la explotación de la ladera N llamada Cueva de los Ladrones. Probablemente, los escombros - pocos por el sistema de mineralización y extracción- y los escoriales fueran reaprovechados durante la época contemporánea. Es evidente que se han ido sucediendo diversos tipos de explotación a lo largo de varios siglos hasta culminar con la gran cava a cielo abierto practicada al $\mathrm{N}$ del castillo. Esta rompió parte de las explotaciones anteriores o bien las sepultó bajo sus enormes escombreras como ocurre en las laderas $\mathrm{N}$ y $\mathrm{O}$.

Sin embargo, a pesar de estas transformaciones, es posible establecer una primera aproximación cronológica. Hemos dicho que la última fase corresponde a la gran explotación a 
cielo abierto. El auge de la minería del Zenete se produce a comienzos del siglo XX. El 5 de abril de 1884 se dio la primera concesión minera de "La Oportunidad", en la que se encuentra el cerro y que, en 1888, pasa a ser propiedad de Hubert Meersmans, un ciudadano belga. A mediados de 1894, la prensa anuncia la construcción de un ferrocarril minero por la compañía francesa "Portman" y al año siguiente se constituye la "Sociedad de las minas de hierro del Marquesado". En los estatutos de la nueva sociedad se afirma que las minas estaban en explotación en ese momento pero sin duda su actividad debía ser modestísima. El capital con el que se contaba era insuficiente $y$, de hecho, dos años despues se arrendó la explotación a la compañía francesa constructora del ferrocaril. Entre las clausulas fijadas en el contrato figura una especialmente interesante para nuestro estudio: La extracción mínima a la que debían ceñirse los pagos a la compañía propietaria se fijaba en 100.00 Tm anuales incluso aunque "durante uno o varios años" no se alcanzase ese umbral, excepto cuando "a juicio de peritos" tal producción no fuera factible "al nivel reconocido por los antiguos trabajos ó sea á cincuenta metros por bajo de la llanura". También se establece "el libre goce de los terrenos necesarios para la explotación á cielo descubierto de las minas, en toda la extensión de la colina de Alquife, situada por cima del nivel de la llanura, salvo en la partes edificadas" (COHEN, 1987: pp. 103-106). No obstante, el decreto de expropiación no llegará hasta mediados de 1899, fecha en la cual quedó también terminada la linea del ferrocarril. A pesar de esto, a fines del mismo año se rescindió el contrato de arriendo mediante un acuerdo en el que se incluía la obligación de la compañía propietaria, Minas de hierro del Marquesado, de comprar "todo el mineral extraido de la mina antes del 15 de enero de 1900" y que en cualquier caso no debía exceder de 40.00 Tm. Ese mismo día se firmó un nuevo contrato, esta vez de venta, con una sociedad de origen escocés con la que comenzará el verdadero despegue de la explotación (COHEN, 1987: pp. 107-108). Como podemos ver por el volumen de mineral, los trabajos apenas si habían comenzado. Eso mismo se deduce del informe de la nueva empresa en 1900, donde se afirma que es "la agricultura el único modo de vida que tienen las poblaciones enclavadas en el Marquesado que en unos 10 kilómetros se encuentran..." y que "gran número de braceros hoy faltos de recursos tienen que salir a buscar trabajo en otras regiones" (COHEN, 1987: p. 109).

A partir de este momento, "The Alquife Mines" comenzará un programa intenso de propección y explotación del yacimiento. Los primeros esfuerzos se encaminaron a completar la prospección iniciada por la filial de "Portman" mediante un amplio sistema de pozos y galerías. La extracción se fue realizando mediante una actividad doble: por una parte a roza, en canteras que seguían los afloramientos y cuyas paredes podían llegar a alcanzar los 40 $m$ de altura. Este era el único sistema empleado para la extracción en 1907 junto con las galerías que partían de ellas. La identificación aquí de los trabajos contemporáneos es relativamente sencilla por su tamaño y técnicas: la presencia de huellas cilíndricas de martillos neumáticos y de marcas en forma cónica de pequeñas detonaciones de las cargas de explosivo. Además, las cavas grandes que extraen las enormes masas de mineral completo necesitan dejar pilares y estribos de roca para sujetar bóvedas y paredes. A partir de estas labores se realizan también galerías regulares, horizontales, con un carácter prospectivo pero desde de las cuales se explotan las vetas de mineral hallado. Tres años más tarde, en 1910, ya funcionaba el pozo S. Pablo como explotación subterránea, lo que no supuso el abandono de las cavas sino que incluso se abrieron algunas nuevas. Además de este pozo maestro se abrió otro más hasta el nivel de la capa freática a partir de los cuales se realizaba la extracción mediante dos sistemas: para la explotación en masas el de "camaras y pilares", que poco despues fue abandonado por el de "franjas horizontales con relleno" y para la explotación de formaciones pseudo-filonianas en "realces", sin apenas entibación ni relleno (PASTOR MENDIVIL, 1948: pp. 303-306).

Es en esta época, sobre todo con el uso de la polvora y de los medios mecánicos, cuando se produce una mayor transformación del cerro. No obstante, parece que buena parte de estas 
canteras ya existían con anterioridad. Así se desprende del plano que en 190I se realiza de las concesiones de la empresa escocesa en la colina y sus inmediaciones ${ }^{4}$. Aquí, un año después de la compra de las minas, además de detallar los tajos en los que se está trabajando y la ya compleja red de galerías abierta, se observan numerosas rozas de gran tamaño. Aún contando con que la empresa "Portman" hubiera comenzado las labores de extracción a cielo abierto tres años antes, su numero y su tamaño son excesivos para una explotación tan breve y en los comienzos del proceso de mecanización. Pero, sobre todo, la mayoría de estas cavas reciben un nombre, a veces incluso bastante significativo. Se denominan, por ejemplo, "Cueva de los Ladrones", "del tío Torcuato", "de la Cabeza", "de las Longueras", "de la Cebada o del Corral", "del Castillo", "de Nicolás", "Bartolo", "de los Almendros", "de los Grajos", "Calera", etc. El que tengan nombres, y además de estas características, significa que no son nuevas, y que podrían incluso referirse en algún caso, como el de la "Cueva de las cinco bocas", a las antiguas explotaciones subterráneas. En muchas ocasiones pues, y como es normal, las labores contemporáneas no hacen sino continuar y aprovechar las precedentes.

Estas parecen estar abandonadas prácticamente en su totalidad a finales del siglo XIX, la actividad no es rentable sin una fuerte inversión de capital que, o bien transforme el mineral en la comarca o sea capaz de llevarlo al puerto de Almería a precios competitivos. Ninguna de las dos cosas suceden, y los nombres de las cuevas a los que nos acabamos de referir indican en muchos casos su abandono o cambio de uso. ¿Desde cuándo se produce esta situación? P. Madoz, en 1845, dice en su "Diccionario" que la colina "se halla llena de minas de hierro, de cuyo arte se estrae muchisimo", pero en ningún momento ofrece dato alguno (MADOZ, I845-1850: p. 33). También afirma que en el vecino pueblo de Jeres "hay una fab. (fábrica) de cobre y 2 de hierro, que entre ambas producen por mitad 1.500 a. (arrobas), la una que en el día corresponde á la casa de Osuna" y que allí mismo se explotan nuevas minas "ferruginosas con liga de plata" (MADOZ, 18451850: pp. 222-223). El mineral se traía en gran medida o casi exclusivamente de Alquife, pero ninguna de estas herrerías parece tener excesiva entidad (GÓMEZ CRUZ, et alii, 1996).

En época moderna la explotación se organizaba mediante el trabajo asalariado pero obligatorio de los vecinos de Alquife y Jeres que extraían y transportaban el mineral y fabricaban carbón. Conservamos un extracto de la merced hecha a los marqueses de los "mineros descubiertos o que se descubriesen de oro, plata, estaño, cobre, hierro, alumbres e otros" 5 . De 1518 es el primer contrato de arrendamiento de las herrerías, propiedad del marqués, del que sólo se conserva un extracto. En I52I el arriendo se hace a Juan Tirador. En el se estipula que "el hierro se habría de labrar a la manera de Vizcaya". En 1552 hay otro contrato por cuatro años. En 1685 las herrerías, propiedad de la Duquesa del Infantado, estaban arrendadas a Francisco jil ${ }^{6}$. También debían funcionar las de la cercana localidad de Lugros en el que se fundían 40 quintales de mineral en $1568^{7}$ y de la que hay una Carta de Poder fechada en $1580^{8}$. No existen referencias sin embargo a los sistemas de extracción del mineral alquifeño o a otros criaderos de hierros como los de Huéneja, Ferreira, Jérez o el propio Lugros. Tampoco sabemos si seguían funcionando en esta época las fundiciones de la ciudad de Guadix, de las que existe un

\footnotetext{
4 Agradecemos la copia y la ayuda proporcionada por J. F. ZUBIAUR, geólogo de la Compañía Andaluza de Minas.

5 Archivo Histórico Nacional. Sec. Osuna, leg. 1895.

6 Pleito de Don Pedro Melchor de Miota Romero, con Francisco jil, vecino de Xerez, arrendador de las herrerías de Xerez, propiedad de la Duquesa del Infantado, 1685. Arch. de la Real Chancillería de Granada, 512-23|3-8, citado por BERTRAND, M. et al.: "Mines et...", p. 191.

7 Archivo de la Chancillería de Granada. 216-D6.

8 Arch. de Protocolos Notariales de Guadix, sin ref. citado por ASENJO SEDANO, C.: Pueblos... p. 213.
} 
privilegio de $15 \mathrm{I}$ I concedido por la reina Juana a Juan de Ordas, corregidor de Guadix, para que extrajera todo el hierro que necesitara para su herrería en Guadix, así de Alquife como de cualquier otro lugar del obispado, de realengo o de señorío 9 . De todas formas, la competencia del hierro vasco hará inviable la explotación a gran escala y la guerra y posterior expulsión de los moriscos en 1568 dejó el Zenete prácticamente despoblado y con su economía gravemente diezmada. Este será un hecho que pesará como una losa sobre el desarrollo posterior de la comarca a lo largo de los siglos XVII y XVIII (ARIAS ABELLÁN, 1984: pp. 3746). En el libro de Apeo de 157| puede leerse: "El lugar de Alquife está asentado en la falda de un cerro donde está un castillo caído (...). Habitado por 140 moriscos con 140 casas todas quebradas, caídas, sin techumbre, e inhabitables y en día sin ningún vecino (...) Tiene Alquife una mina de donde se saca hierro para las herrerías, la una de Jérez y, la otra, de Lubros" ${ }^{10}$. En el Apeo de La Calahorra (folio 3) se dice que la marquesa "tenía en la villa de Jérez unas herrerías que le rentaban entre 800 y 1000 ducados anuales y para hacer el hierro tenía los montes y sus arbolados de los cuales los vecinos de Jérez y su barrio de Alcázar estaban obligados a trabajar en las herrerías y a ayudar a hacer el hierro por un moderado precio cuando trabajan, asimismo, estaban obligados a ayudar a hacer carbón para las herrerías al precio de 60 marravedíes por cada carga y la mena que es la materia de hierro se llevaba de la queba de la villa de Alquife, la cual eran obligados a la saca y llevar los vecinos de la dicha villa de Alquife y por 30 maravedíes cada carga puesta en las dichas herrerías".

La minería de época moderna está descapitalizada y es dependiente del marqués. El hecho de que no haya sistemas de explotación complejos antes de 1900 prueba que la minería debe mantenerse a un nivel muy primario. También es cierto que el tipo de mineraliza- ción y la topografía permiten, a través de técnicas simples, la explotación de grandes masas de mineral poco profundas o incluso superficiales sin problemas de desagüe ni casi de entibación. Precisamente ahí radicó gran parte del éxito inicial de "Alquife Mines". Es casi seguro incluso que ni siquiera se utilizara la pólvora y los barrenos para la extracción -empleados en Europa al menos desde el siglo XVII (PIERRE, 1993: pp. 4|4-4I5)- hasta la llegada del sistema de explotación plenamente capitalista con las compañías extranjeras. Pero si hemos dicho que el plano de 1901 y la toponimia de las "cuevas" nos permiten afirmar que existían con anterioridad, ¿cuándo comienza esta explotación a cielo abierto? Si nos fijamos en la ladera Sur, donde se ubica la alquería medieval, no parece probable la coexistencia de este sistema de explotación con la presencia del poblamiento, parcialmente destruido por las cavas y sus derrumbes.

Por otra parte, hemos documentado un laboreo subterráneo en estrechas e irregulares galerías y cámaras al que precede una pequeña explotación superficial, en forma de trinchera o no, pero que, en cualquier caso e inexplicablemente, no llega a agotar las masas de mineral aflorante en la superficie. La posibilidad de que se despreciara este mineral para buscar otro tipo de mineralización distinta queda descartada ya que toda esta constituida por goethitas. Es por tanto una estrategia de explotación que no sabemos a que criterio responde: ipor la proximidad del poblamiento?, ipor desconocimiento del tipo de mineralización?, ipor tradición minera en las explotaciones filonianas del pie de monte de Sierra Nevada? Un ejemplo claro lo encontramos en la denominada "Cueva de las cinco bocas" que en realidad son varias explotaciones pequeñas contiguas: tras un arañado superficial de la masa de mineral aflorante se practica una galería estrecha y una camara algo mayor, de unos dos metros de altura. Toda ella esta llena de hue-

\footnotetext{
9 Archivo General de Simancas. Registro General del Sello. I5I I, Junio, s.f.

10 Archivo de la Chancillería de Granada. 216-D6.
} 
llas trabajo con puntero de sección cuadrada que, ahora si, ha agotado el mineral subterráneo. Gran parte de la cámara está recubierta de una capa negra que no son restos de fuego para el abatimiento del hierro, tanto por su textura como porque recubre las trazas del puntero que por tanto son anteriores. Se trata de una concreción de manganeso filtrado a través de los mármoles tras el laboreo de la mina que también rellena en parte las cavidades de calcita cristalizada donde ha llegado a precipitar a modo de pequeñas estalactitas. Es, por tanto, una explotación antigua. Son este tipo de explotaciones las que a nuestro juicio podrían ponerse en relación espacial con la existencia de la alquería. Es posible que por razones de seguridad, se optase por la explotación subterránea tras ese arañado superficial del mineral aflorante. Solo cuando la alquería se baje al llano, por debajo de la linea de rigidez marcada por la acequia e invadiendo parte de las tierras de regadío y cuando se rompa la antigua relación espacial entre el castillo y la población, será posible comenzar, a instancias ahora del marqués, la explotación a cielo abierto de las masas completas de mineral. Así sucede también en Italia, donde serán los Medici, a final del s.XV y en el XVI, los que comenzarán en Toscana la extracción a cielo abierto, destruyendo parte de las galerias antiguas pero practicando al mismo tiempo otras nuevas más profundas (FRANCOVICH, sin fecha; pp. 35-38). No sería de extrañar incluso una influencia en este mismo sentido por la estrecha relación del primer marqués, constructor del renacentista e italianizante castillo-palacio de La Calahorra con Italia.

Sea como fuere, muchas de estas labores subterráneas están rotas por otras posteriores a cielo abierto o también subterráneas, siempre de mayores dimensiones, que dejan galerías y cámaras colgadas en sus paredes, cornisas y bóvedas. Por las razones que hemos dicho de proximidad a la alquería y la presencia de otro tipo de explotación bajo tierra que deja parte del mineral en superficie sin extraer pensamos que la minería a cielo abierto, más allá de un arañado superficial o una trinchera pequeña debe corresponder a la época moderna, tal vez con la cesión de los criaderos al marqués en 1526. Esto, sin embargo, no tiene porqué suponer una intensificación de la explotación ya que, aunque la organización del trabajo no fuera la misma bajo el señorío que en época nazarí, la orientación agrícola de la economía va a seguir persistiendo. Tampoco tiene porqué suponer un abandono de las labores subterráneas que parecen continuar con la misma técnica siguiendo el filón de forma irregular y utilizando la maza y el puntero cuyas huellas son visibles a lo largo de numerosas explotaciones de este tipo. Por estos motivos nos es imposible por ahora, y ante la falta de documentación escrita, una distinción más allá de lo expuesto hasta el momento.

Ya hemos visto también algunos aspectos de la explotación andalusí y la problemática en relación a la transformación del mineral. Las minas podrían ser propiedad de los reyes nazaríes. Así se desprende de las fatwas - dictámenes jurídicos- recopiladas por al-Wanșarìsī a finales del siglo $X V$. Afirma que las minas se otorgan como concesión y que no pueden ser constituidas como habiz ya que no forman parte de la herencia del beneficiario, sino que a su muerte son concedidas a otra persona (LAGARDÉRE, 1995: p. 220). En este caso la concesión llevaría aparejado un arriendo por el usufructo de la explotación (LAGARDÉRE, 1995: p. 332). Sin embargo, también se da el caso de que un particular pueda ser propietario de una mina o, en los casos que recoge al-Wanșarīisi, de una parte de ella junto con otros muchos socios (LAGARDÉRE, 1995: pp. 358 y 415). En Alquife, por la relación entre las explotaciones y el castillo, no sólo de proximidad, sino también por la presencia de mineral y escorias en su obra -especialmente como decoración-, pensamos que las minas deberían pertenecer a los monarcas. No es de extrañar también si tenemos en cuentra el nivel de centralización alcanzado por los nazaríes y la gran cantidad de propiedades que estos parecen tener en el Zenete (GONZÁLEZ PALENCIA, 1940). El hecho de que las minas se encuentren tan cercanas al castillo debe responder a la necesidad de un control directo de la producción, aunque no fuera este el único factor a la hora del establecimiento de la alquería y el castillo. Este control lo ejercería el alcaide como representante del 
estado. Ahora bien, no podemos saber si la explotación se realizaba a través de un arriendo o no, ni la forma de organizar el trabajo o la capacidad productiva, tanto extractiva como metalúrgica, hasta la realización de un estudio mucho más detallado que incluya la excavación sistemática del yacimiento. De todas formas el trabajo de los campesinos debía ser estacional o esporádico, como complemento de la actividad agrícola y no de forma especializada. Es posible que hubiera alguna persona con dedicación exclusiva, pero la opción por el sistema de agricultura intensiva y el mantenimiento del mismo hace incompatible su existencia con una especialización minera. En I550, el campo y el secano, que no eran propiedad privada, son objeto de fiscalización por los marqueses solo indirectamente a través de un impuesto que grava la posesión de un animal de labranza llamado "renta del campo". Esta se unía a la gabela, impuesta desde I5I5 y llamada "pan del campo", repartida localmente y expresión del volumen de tierras roturadas que los campesinos aprovechaban "'. De ella nos es posible deducir que el aprovechamiento no era facilmente controlable por lo que el impuesto se establecía por municipios y que no en todos los pueblos tiene la misma importancia, incluso en Alquife no se recoge porque apenas si se explota el campo (MARTIN CIVANTOS, en prensa). El hecho de que no se trabajen apenas las tierras fuera del regadío indica que ese tiempo y fuerza de trabajo son aprovechados en la explotación minera, sin duda más rentable que los secanos. Sin embargo, desconocemos como se organizaba el trabajo que, como en época moderna, debía ser asalariado, pero difícilmente obligatorio.

En cualquier caso esto no supone que la minería y siderurgia del hierro no gozaran de importancia. Es una actividad económica estratégica, no solo para el propio desarrollo de la agricultura, sino también de cara a la situación de guerra con Castilla a partir del siglo XI. En este sentido, el hierro es un sector de altísimo interés, cuya producción es necesario estimular y controlar para garantizar el abastecimiento. El transporte de parte del hierro a la ciudad de Guadix, con el consiguiente esfuerzo de llevar el mineral y el carbón, podría responder a una estrategia de mayor control o de incentivación a través de las exenciones tributarias ${ }^{12}$, pero en cualquier caso, responde a ese empeño por su producción. Son necesariamente muchos los interrogantes que, como dijimos antes, quedan sin resolver a la espera de proximas investigaciones. Aquí hemos planteado algunos de ellos, pero sin duda se hace necesario un estudio sistemático, que por supuesto incluya la excavación del yacimiento y el análisis de las zonas de explotación y transformación del mineral.

\section{BIBLIOGRAFÍA}

ARIAS ABELLÁN, Jesús (1984): Propiedad y uso de la tierra en el Marquesado del Cenete. Granada, pp. 37-46.

ASENJO SEDANO, Carlos (1992): Pueblos e iglesias de Granada. Siglo XVI. La tierra de Guadix. Granada.

BERTRAND, Maryelle; SÁNCHEZ VICIANA, José R. y ZUBIAUR MARCOS, J. F. (1996): "Mines et metallurgies médiévales de la Sierra Nevada (region de Guadix, prov. de Grenade). Premieres donnees", en Actas de las I Jornadas sobre Minería y tecnología en la Edad Media peninsular (León, 1995). León, pp. 180-197.

COHEN, Aaron (1987): El Marquesado del Zenete. Tierra de Minas. Granada.

ESPINAR MORENO, Manuel (1987): "El reparto de aguas del río Alhama de Guadix en el siglo XII ( I 139)", en Estudios sobre Málaga y el Reino de Granada en el V Centenario de la Conquista. Málaga, pp. 235-255.

ESPINAR MORENO, Manuel; ÁLVAREZ DEL CASTILLO, M. Angustias y GUERRERO LAFUENTE, M. Dolores: La ciudad de Guadix en los siglos XV y XVI (149015/5).

FRANCOVICH, Riccardo (199I): Rocca S. Silvestro. Roma.

FRANCOVICH, Riccardo (Ed.): Pannelli. San Silvestro. Parco archeominerario.

\footnotetext{
II Ar.Ch.Gr. 506-1070-4, cita de ESPINAR MORENO, M. et al.: El marquesado del Cenete..., pp. I 60-I 62.

12 Ver nota I.
} 
GÓMEZ CRUZ, M; GIMÉNEZ YANGUAS, M; REYES MESA, J.M. y RUBIO GANDÍA, M.A. (1996): "Las herrerías en la vertiente norte de Sierra Nevada", en I Conferencia Internacional. Sierra Nevada. Conservación y Desarrollo Sostenible. Granada, pp. I17-125.

GONZÁLEZ PALENCIA, Alonso (1940): "Documentos árabes del Cenete (siglos XII-XV)", en al-Andalus, V ( 1940), pp. 30I-382

GONZÁLEZ PALENCIA, Alonso (194|):"Adición a los documentos árabes del Cenete", en al-Andalus, VI ( 194I).

GONZÁLEZ ROMÁN, Cristobal; ADROHER AUROUX, Andrés M. y LÓPEZ MARCOS, Antonio (1997): "El peñón de Arruta (Jéres del Marquesado, Granada): una explotación minera romana", Florentia lliberritana. Revista de Estudios de Antigüedad Clásica. VIII, pp. 183-2I3.

HUMBERT, André (1988): "Le Marquesado del Zenete, signification géographique d'une comarca", en Sierra Nevada y su entorno. Actas del encuentro hispano-francés sobre Sierra Nevada. Granada, pp. 9-29.

IBN AL-JAȚīB ( 1 987): Mi'yar al-ijtiyar fi dikr al-ma'ahid waI-diyar. Texto árabe. trad. y estudio por CHABANA M.K. S.I, 1977

IDRĪST̄ (1989): Los caminos de al-Andalus en el siglo XI según "Uns al-Muha' wa-rawd al-fura"'. Ed. y trad. Jassim ABID MIZAL. Madrid.

LAGARDÈRE, Vincent (1995): Histoire et société en occident musulman au moyen âge. Analyse du "Mi'yär" d'al-Wanșarisis. Madrid.

LÉVI-PROVENÇAL, Evaristo y GARCÍA GÓMEZ, Emilio (1980): El siglo XI en primera persona. Las "memorias" de "Abd Allah, último rey zirí de Granada destronado por los almorávides (1 090). Madrid.

MADOZ, Pascual (1987): Diccionario Geográfico, Estadístico, Histórico de España y sus posesiones de Ultramar. Granada. Madrid, 1845-1850, ed. facs. Salamanca, 1987.

MALDONADO CABRERA, G. RUIZ SÁNCHEZ, V. y CASTILLA SEGURA, J. (|99|): "Intervención de urgencia en el yacimiento de El Cerro de Juan Canal, Ferreira (Granada)", en Anuario Arqueológico de Andalucía. 1989. Sevilla, pp. 186-189.
MALPICA CUELLO, Antonio (1996): Poblamiento y castillos en Granada. Barcelona.

MARTÍN CIVANTOS, José Ma (en prensa): "Transformaciones del paisaje en el Zenete (Granada): la creación de las vegas", en Primeras Jornadas de Historia Rural y Medio Ambiente en la Andalucía Medieval (Almonte, 23-25 de Mayo del 2000).

MARTÍN CIVANTOS, José Ma (inédito): Fortificaciones y organización del territorio en época medieval en el Zenete (Granada).

MARTÍN GARCÍA, Mariano; BLEDA PORTERO, Jesús y MARTÍN CIVANTOS, José Ma (1999): Inventario de arquitectura militar de la provincia de Granada (ss.VIII-XVIII). Granada.

MOLINA LÓPEZ, Emilio (|99|): "El documento árabe de Guadix (s.XII)", en Homenaje al Profesor Jacinto Bosch Vila. Granada, t. I, pp. 27I-292.

PASTOR MENDIVIL, M.: "Estudio geológico y minero del yacimiento de Alquife y Marquesado", en Boletín del Instituto Geológico y Minero de España, LXI (1948), pp. 207-317.

PIERRE, F. (1993): "Étude de l'apparition de la poudre noire dans l'évolution des techniques minières de percement", en Archeologia delle attivitá estrattive e metalurgiche. V ciclo di lezioni su la richerca applicata in archeologia. Florencia, pp. 4/3-423.

RUIZ MONTES, Manuel (|99|): "Minas y minería en Andalucía Oriental", en FERRER, M., S.I. y MORA TERUEL, F.: Minerales de Granada. Sierra Nevada. Granada.

RUIZ MONTES, Manuel (1996): "Los recursos minerales de Sierra Nevada y las Alpujarras", en $1{ }^{a}$ Conferencia Internacional: Sierra Nevada. Conservación y desarrollo sostenible. Vol. I. Madrid, pp. 337-35I.

TRILLO SAN JOSÉ, Carmen (1996): "Los diferentes aprovechamientos del agua en una alquería del Reino de Granada: La Malahá, del distrito del Quempe", en Agricultura y Regadío en al-Andalus. II Coloquio de Historia y Medio Físico. Granada, pp. 215-228. 


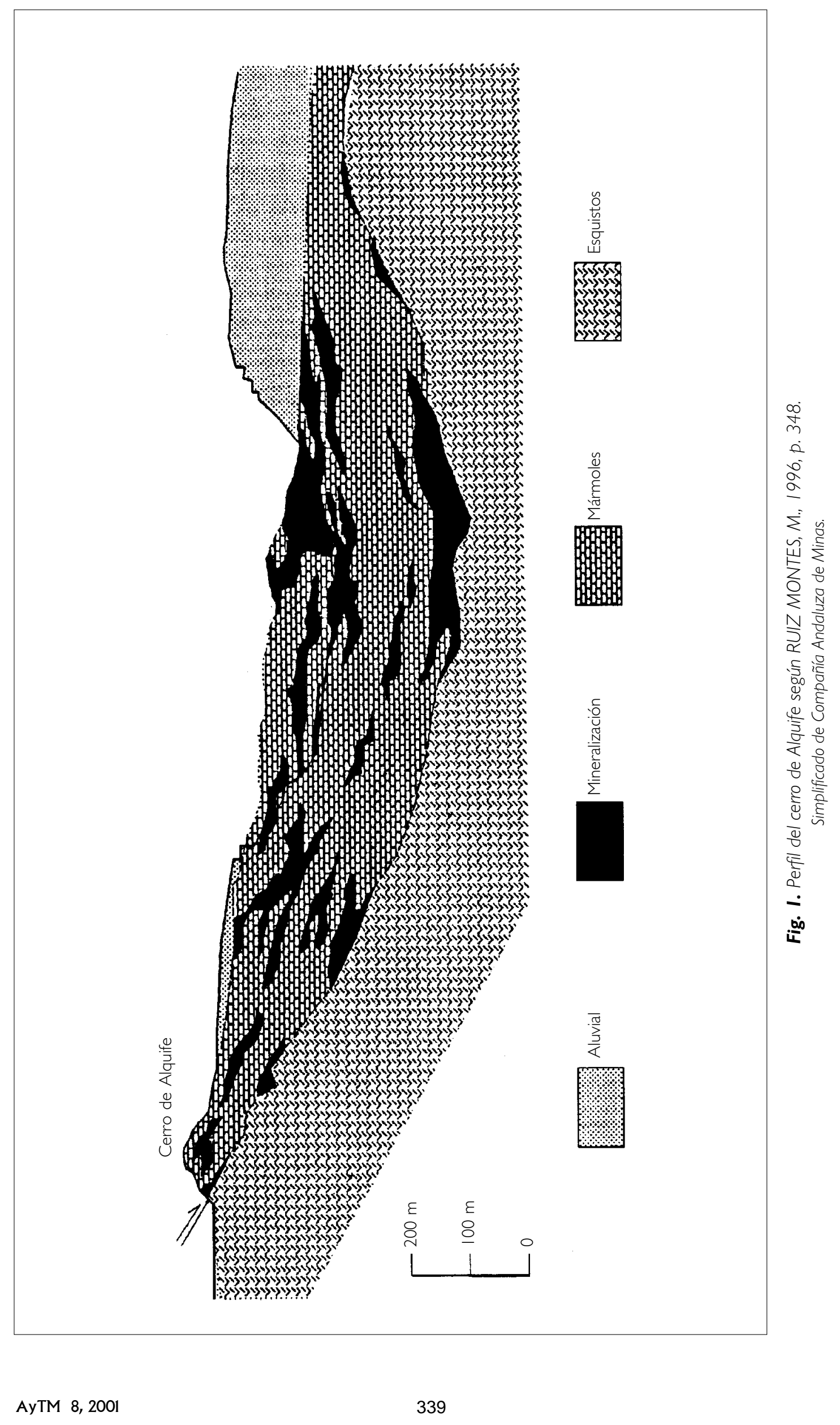




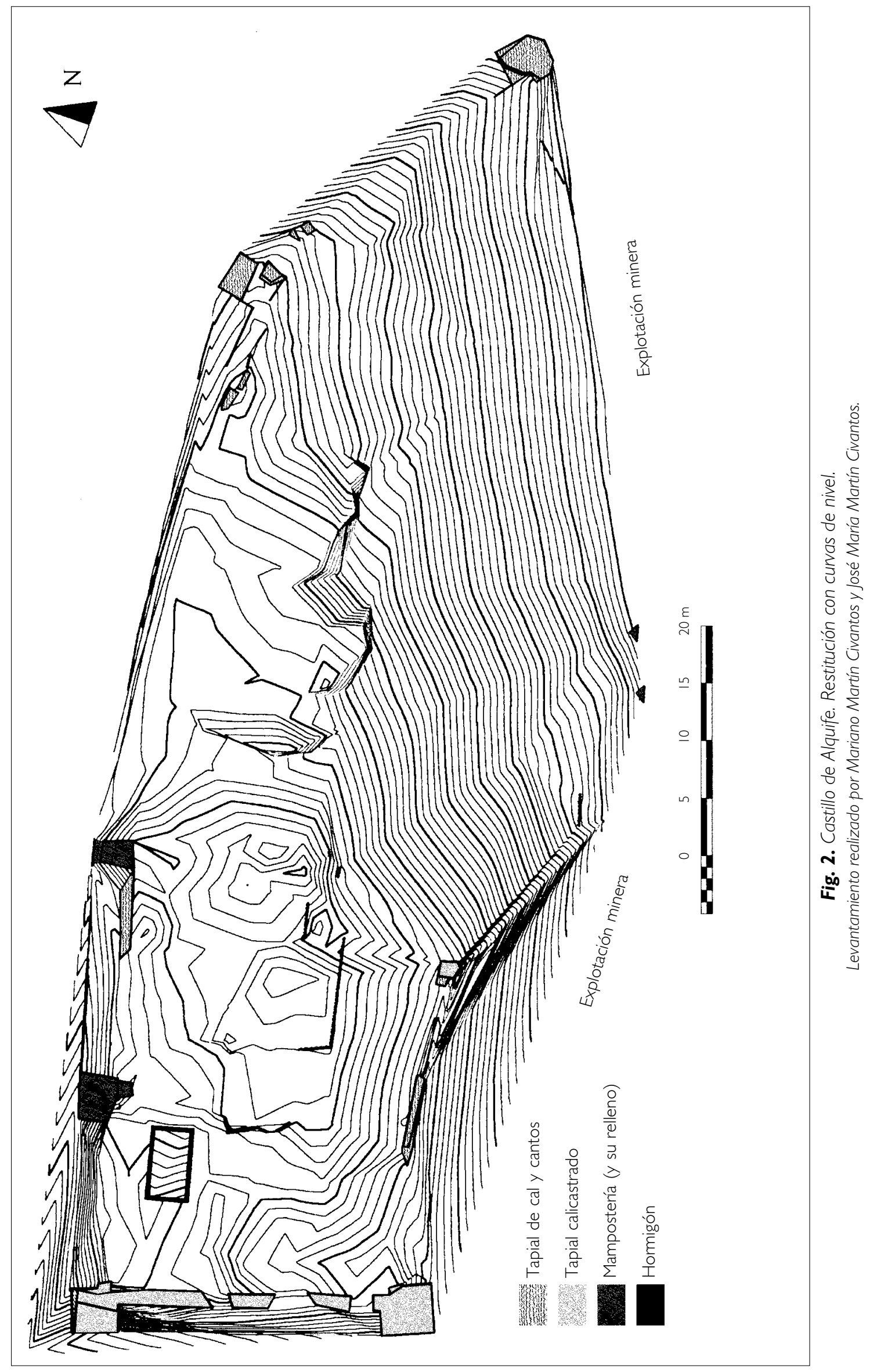




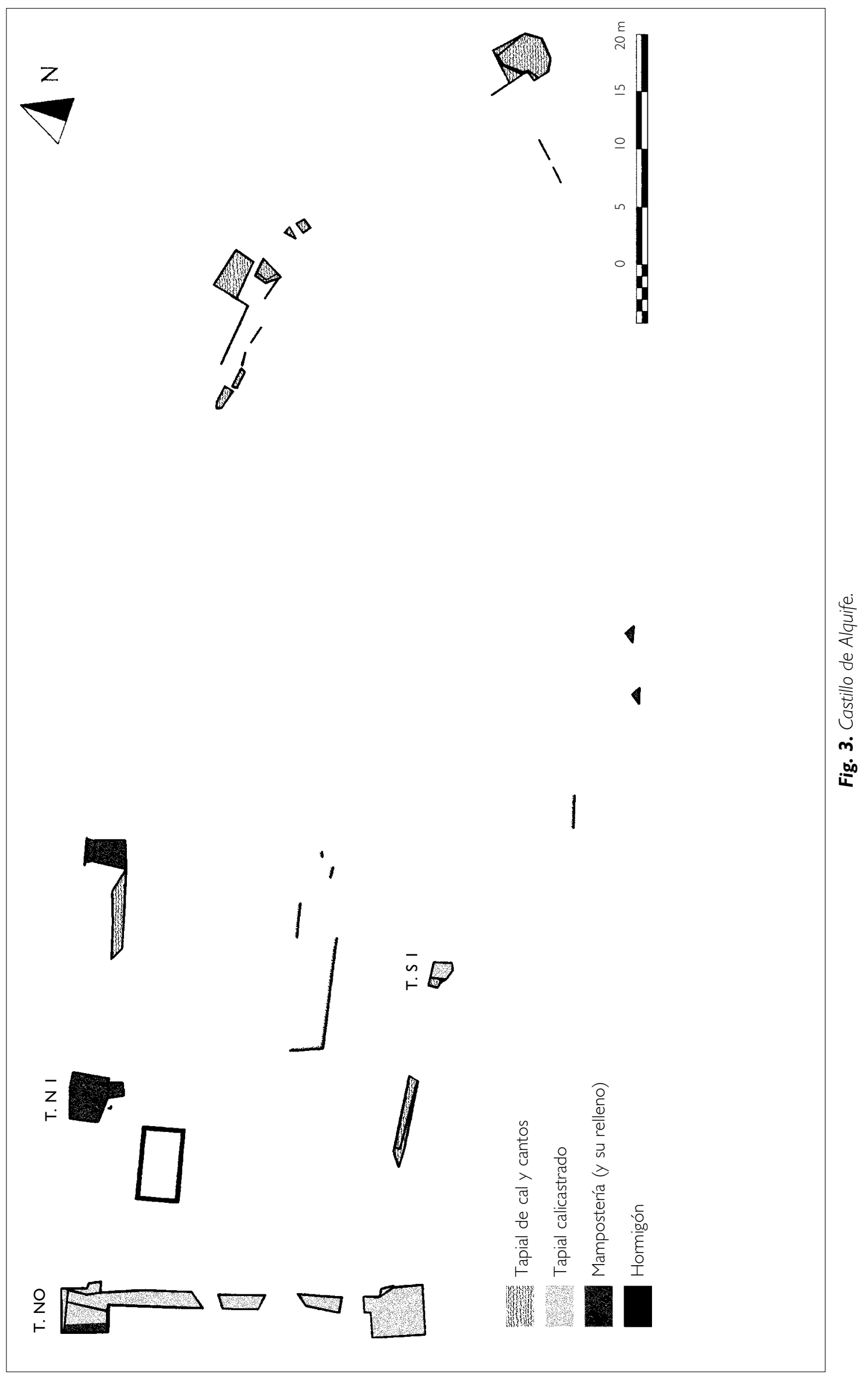



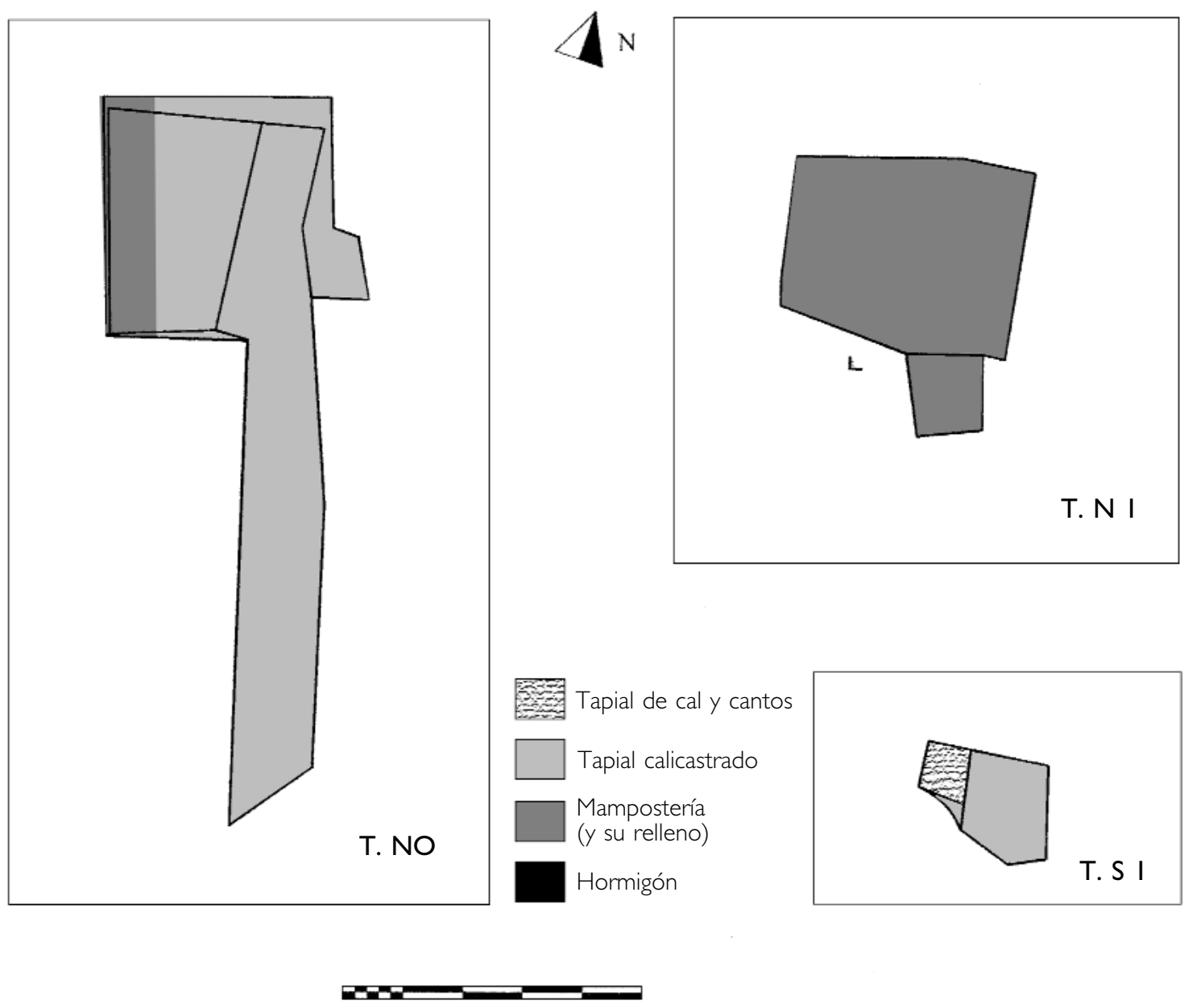

Fig. 4. Detalle de las torres. 


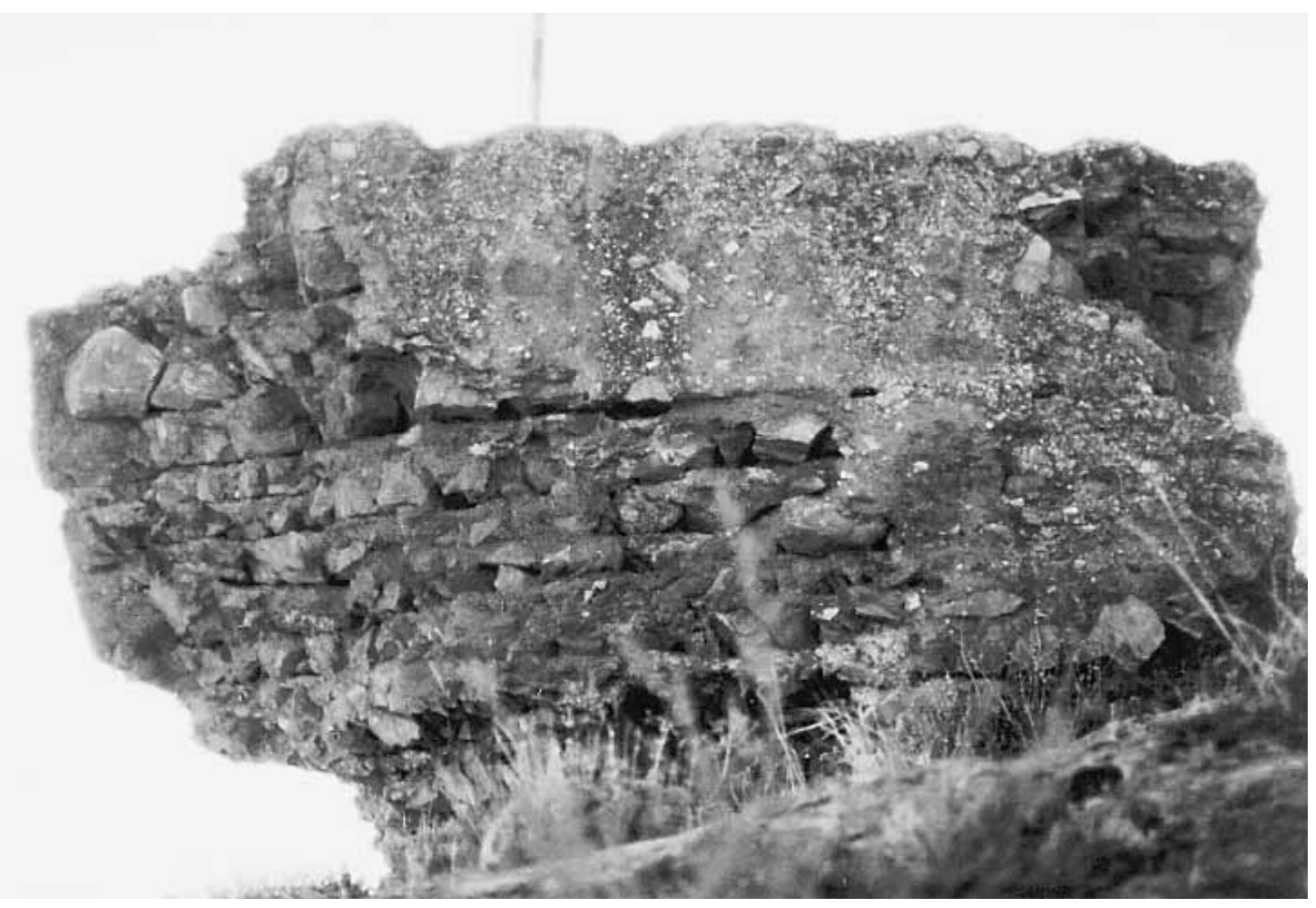

Fig. 5. Torre E. Detalle de la construcción en cal y cantos.

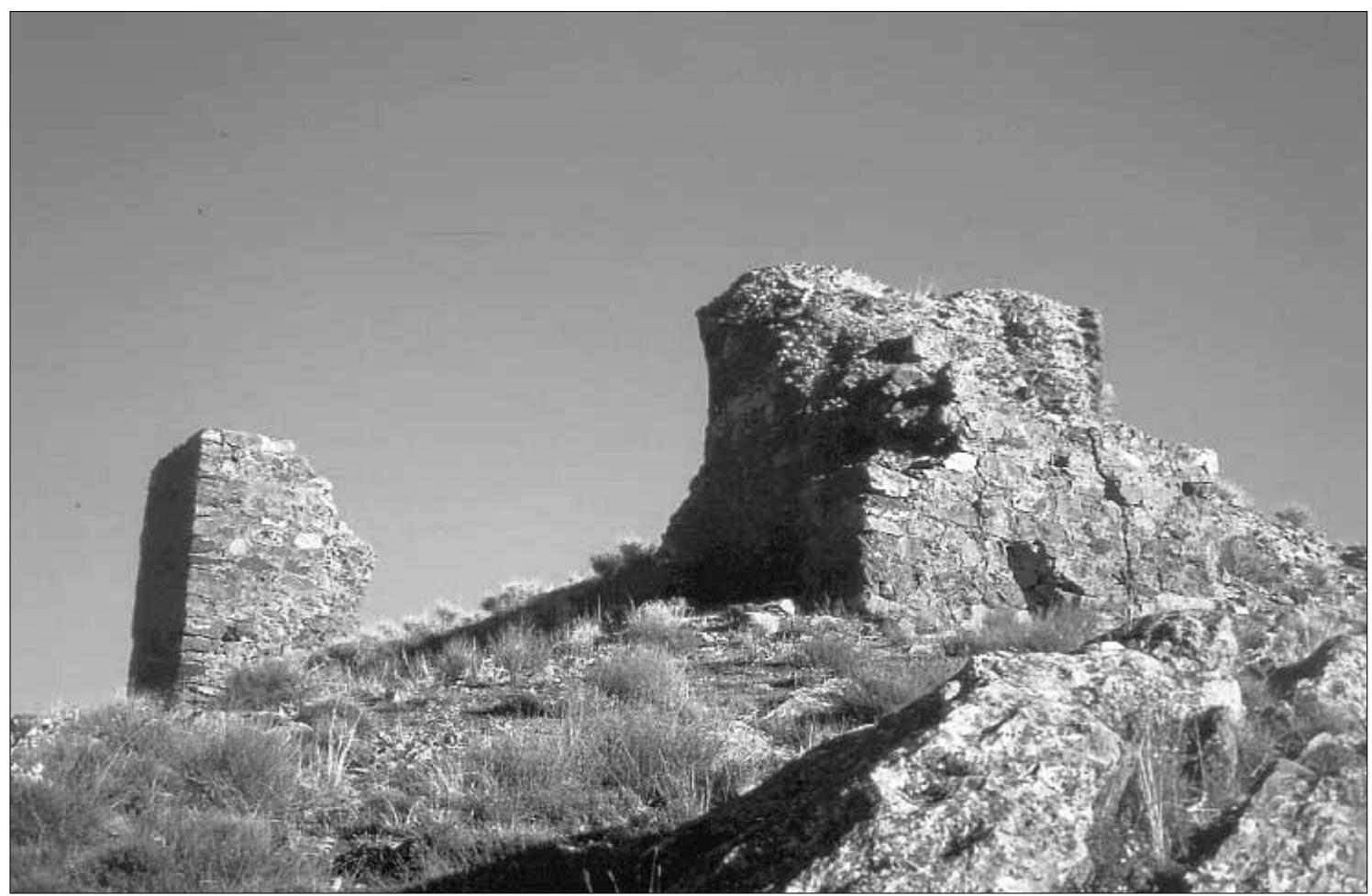

Fig. 6. Torre NO en primer plano y TNI en segundo. 


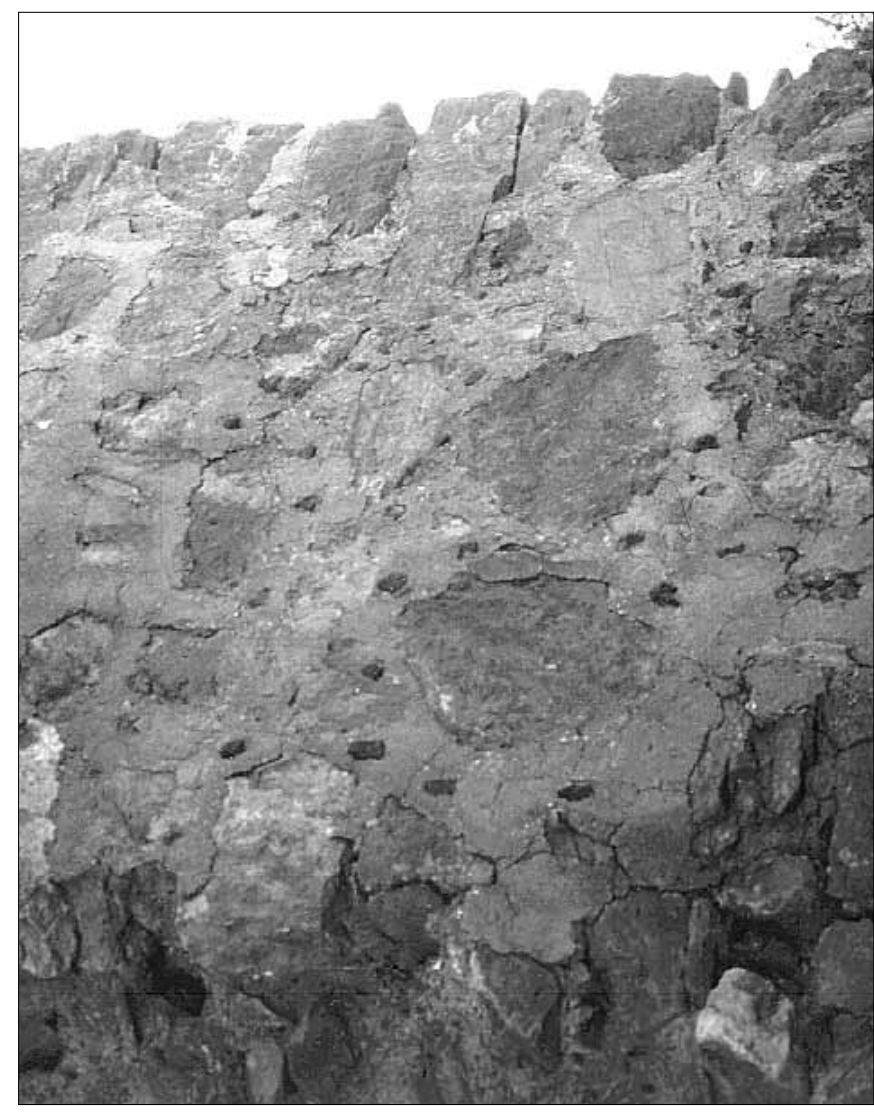

Fig. 7. Torre TNI. Detalle de la reparación (esquina inferior izquierda) y de la decoración con escorias.

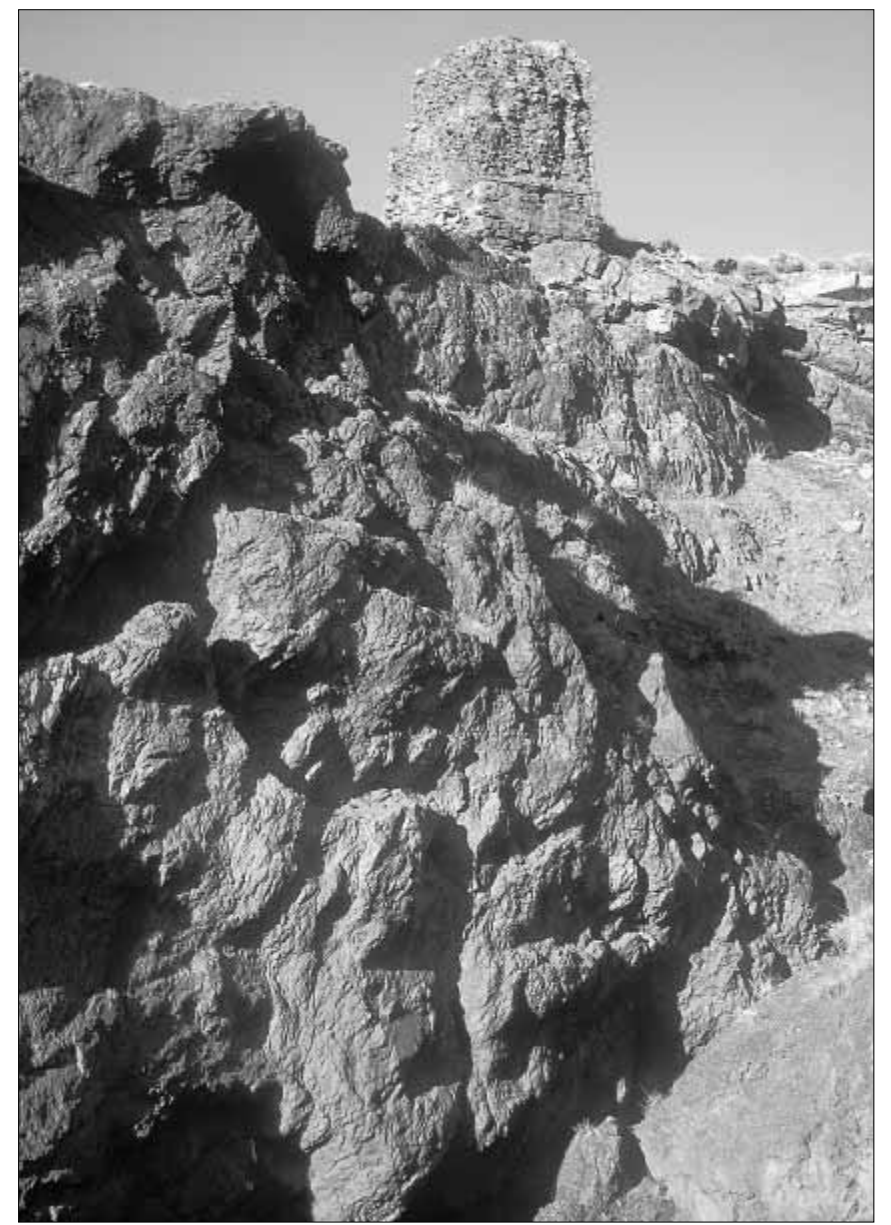

Fig. 8. Torre SO y explotación a cielo abierto que rompe las antiguas minas. 


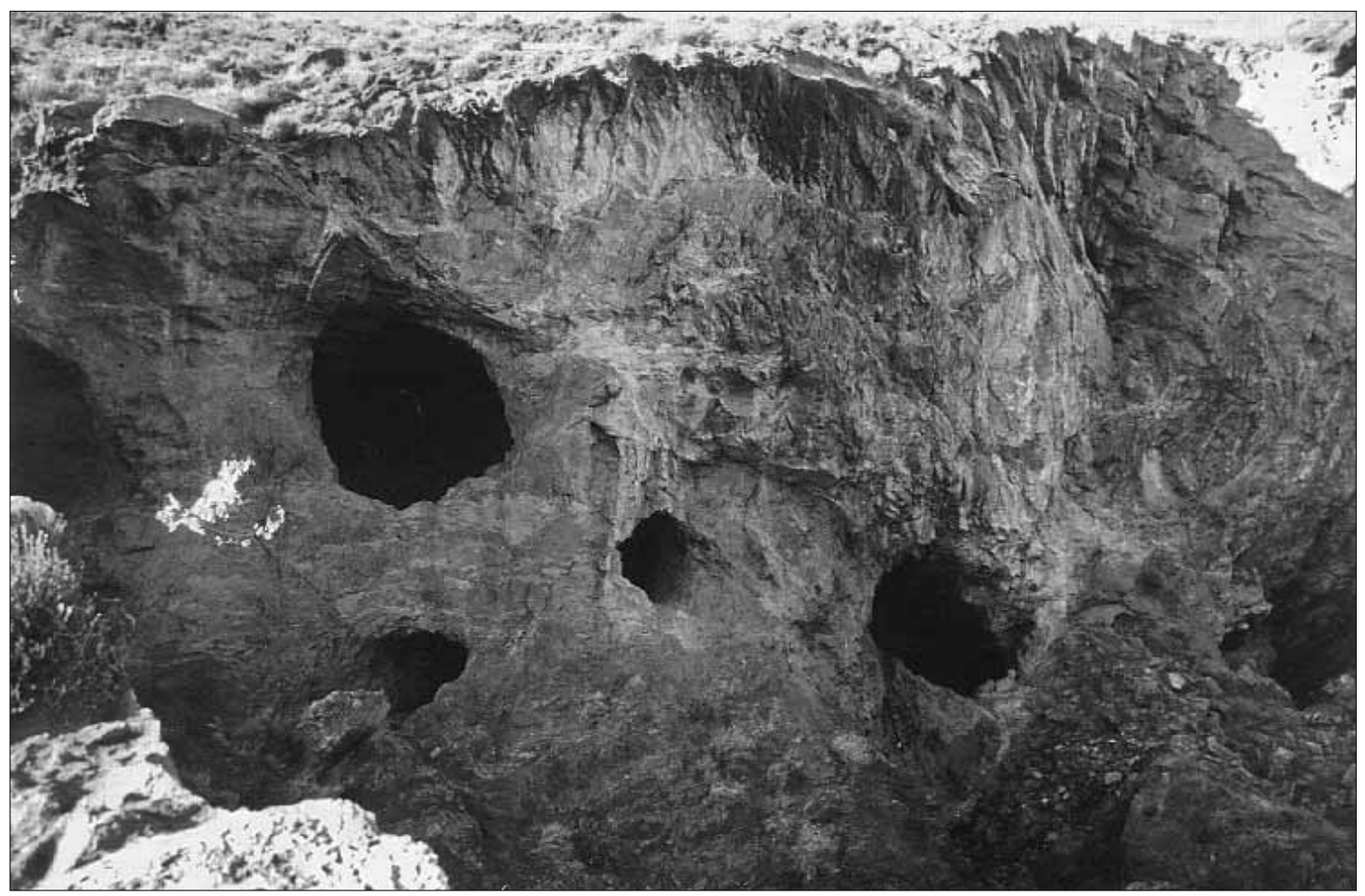

Fig. 9. Minas de la ladera S.

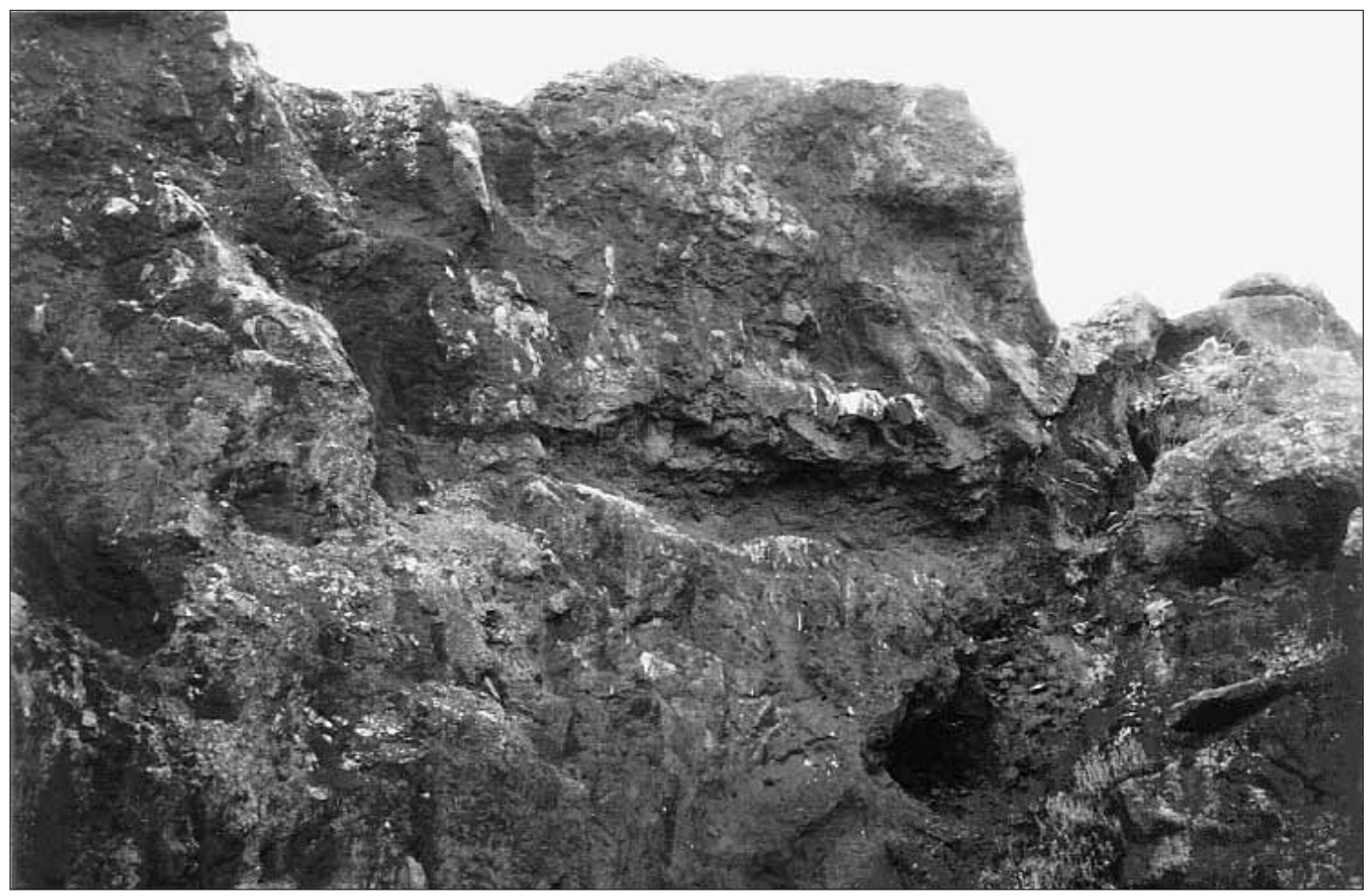

Fig. 10. Minas de la ladera NE. Las explotaciones a cielo abierto rompen las galerías antiguas de formas irregulares que quedan colgadas en el perfil. 